\title{
УДК 331 \\ ЭКОНОМИЧЕСКИЙ И СОЦИАЛЬНЫЙ РОСТ - ПРОБЛЕМЫ ЭФФЕКТИВНОСТИ ИСПОЛЬЗОВАНИЯ РАБОЧЕГО ВРЕМЕНИ И СОКРАЩЕНИЯ РАБОЧЕЙ НЕДЕЛИ
}

\author{
В.Г. Беломестнов, д.э.н., профессор \\ ФГБОУ ВО «Восточно-Сибирский государственный университет технологий и управле- \\ ния», г. Улан-Удэ, Россия
}

\begin{abstract}
Аннотация. В статье рассмотрено влияние инновационных изменений на характеристики социально-экономической. Показано, что основным опасением населения в соперничестве с искусственным интеллектом и автоматизацией все-таки является занятость и боязнь потери рабочих мест, обнуление компетенций и профессиональных квалификаций. Определены препятствия и недостатки реализации национального проекта создания высокопроизводительных рабочих мест. Рассмотрен вопрос о введении четырехдневной рабочей недели. Определено, что с позиции экономического развития учитывая значительное отставание России по макроэкономическим показателям, мы пока не можем позволить себе роскошь сокращения фонда рабочего времени. Выявлено, что возможность получения социального эффекта также сомнительна. Определено, вопрос о введении четырехдневной рабочей недели в России еще не созрел и это дело достаточно отдаленного будущего.
\end{abstract}

Ключевые слова: инновачионная экономика, занятость, высокопроизводительные рабочие мета, сокращенная рабочая неделя, экономический рост.

\section{ECONOMIC AND SOCIAL GROWTH - PROBLEMS OF EFFECTIVENESS OF USING WORKING HOURS AND REDUCING WORKING WEEKS}

V.G. Belomestnov, Doctor of Economics, Professor

East-Siberian state University of technology and management, Ulan-Ude, Russia

Annotation. The article considers the impact of innovative changes on the characteristics of socio-economic. It is shown that the main fear of the population in the rivalry with artificial intelligence and automation is still employment and fear of job loss, zeroing of competencies and professional qualifications. Obstacles and weaknesses in the implementation of the national project for creating high-performance jobs were identified. Considered the introduction of a four-day work week. It has been determined that, from the perspective of economic development, given Russia's significant lag in macroeconomic indicators, we cannot yet afford the luxury of reducing the working time fund. It was revealed that the possibility of obtaining a social effect is also doubtful. It is determined that the question of introducing a four-day work week in Russia has not yet matured, and this is a matter of a rather distant future.

Key words: innovative economy, employment, high-performance working meta, shortened working week, economic growth.

Инновационные изменения, в том числе внедрением принципов цифровой экономики и искусственного интеллекта, неизбежно приводят к системным изменениям экономики.

Любые инновации меняют такие характеристики социально-экономической системы как «труд работников и его структуру (долю труда высшей, средней и начальной профессиональной квалификации в продукции); затраченные другие ресурсы и их структуру (доля различных видов ресурсов в валовом продукте); издержки экономики (доли различных видов издержек и прибыли в цене)» [1]. 
Основным опасением населения в соперничестве с искусственным интеллектом и автоматизацией все-таки является занятость и боязнь потери рабочих мест, обнуление компетенций и профессиональных квалификаций[2].

Джоанна Брайсон считает, что искусственный интеллект становится политическим фактором. За счет того, что он заменяет людей, вытесняет их с рынка труда, увеличивается экономическое неравенство. Все риски в этом случае, должны брать на себя правительства [3].

Первым этапом реализации принципов инновационной экономики в регионах России является повышение производительности труда. Цель данного процесса в поднятии общего технологического уровня производства, переход к новым технологическим укладам. Процесс создания высокопроизводительных рабочих мест основан на внедрении высокотехнологичного оборудования и современных методов организации производства, которые должны иметь мультипликативный эффект для деятельности предприятий

Россия в настоящее время активно реализует национальный проект создания высокопроизводительных рабочих мест. Как и в других случаях, были созданы институты развития, в частности федеральный центр компетенций в сфере производительности труда. По словам директора данного центра Николая Соломона к 2024 году данный показатель выйдет на уровень прироста руда 5\% в год. В настоящее время мы вдвое отстаем по производительности от европейских стран [17].

Помощь по данной программе оказывается предприятиям не сырьевого сектора с выручкой от 400 миллионов до 30 миллиардов рублей и с долей иностранного капитала в уставном капитале не более 25\%. Такой подход позволяет сосредоточить финансы на базовых предприятиях ключевых отраслей промышленности и, прежде всего, обрабатывающих, которые по задумке идеологов программы являются системообразующими для экономики.

К некоторым недостаткам этой концепции является недостаточное внимание коммерческим проектам в социальной сфере, науке, образовании и в других отраслях, которые также выпускают интеллектуалоемкую продукцию с высокой производительностью

К другому недостатку относится выход за рамки критериев финансовой поддержки деятельность большинства малых предприятий, в том числе инновационных, а также начинающих, растущих компаний.

Однако в России в настоящее время действуют множество институтов поддержки таких организаций и проектов, которые через прямое финансирование и гранты позволяет развивать производительность.

Производительность рабочего места традиционно определяют по трудоемкости продукции, выработке или по средней зарплате работников.

Трудоемкость производства продукции хотя и отражает степень механизации и автоматизации труда, но при этом является одной из характеристик применяемой технологии и оборудования. По этому, сама по себе, характеристика трудоемкости изготовления не в полной мере отражает эффективность бизнеспроцесса, особенно для макроэкономики региона в целом.

Вопрос об использовании показателя выработки является также спорным, так как она определяется в числе прочих факторов условиями рынка и рентабель- 
ностью продукции (производства), которая во многих случаях не является прямым результатом эффективности управления.

Заработная плата, сама по себе, также не может быть полноценной и единственной характеристикой производительности в условиях инновационной экономики. Пол Мейсон считает, что все технологии, изобретенные до сих пор, обесценивали труд и часть продуктов. Как следствие Б. Шиллер считает, что инновационная экономика приведет к стагнации заработной платы и к изменению структуры себестоимости в сторону увеличения расходов на содержание и амортизацию оборудования, разработку и обслуживание интеллектуальных не материальных активов [5].

Создание высокопроизводительных рабочих мест имеет определенные пределы обусловленные:

- «необходимостью обеспечения макроэкономического равновесия между выпуском продукции и услуг, ценами на них, денежной массой и покупательской способностью населения и бизнеса;

- необходимостью соблюдения базовых принципов организации производства - пропорциональности рабочих мест, ритмичности, комплексности, системности и др.;

- отсутствием высокотехнологичных инноваций в ряде отраслей;

- экономической целесообразностью внедрения инноваций;

- а также рядом других факторов» [6].

Цель создания высокопроизводительных рабочий мест в отраслях экономики является не углубление дифференциации заработной платы, а обеспечение ее роста по предприятиям и отраслям в целом.

В связи с эти процесс создания высокопроизводительных рабочих мест должен сопровождаться комплексной модернизацией всего производственного процесса, поднятия производительности по всем рабочим местам.

В случае высвобождения низко производительных рабочих мест должна быть разработана программ диверсификации занятости работников.

По мнению Малышева Е.А. процессы повышения производительности труда являются залогом устойчивого развития регионов [7].

Олег Шеинсчитает, что в рамках исчезновения ряда профессий в будущем уже скоро 15 миллионов россиян могут потерять работу из-за того, что ихпрофессии окажутся невостребованными на рынке [8].

Следует отметить, что именно цифровые технологии могут поспособствовать совершенствованию перечня востребованных компетенций и профессий. Так, в настоящее время идет постоянное развитие списка требуемых компетенций и профессий. Максим Топилин заявил, что сформировано почти 1300 профессиональных стандартов, как в традиционных, так и в новых профессиях [9].

По данным доклада BCG и WorldSkills в России в «квалификационную яму» попадает 33,9 млн. человек, то есть это работники, компетенции которых избыточны или недостаточны для выполнения работы, а в мире таких работников около 1,3 млрд. человек, то есть каждый третий [10].

В докладе PewResearchCenter содержаться крайне пессимистические выводы о том, что ценность образования будет девальвироваться точно так же, как и отдача от человеческого труда [11]. 
«Начиная с 1991 года, в России установлена максимальная продолжительность рабочего времени, которая составляет40 часов в неделю с 2 выходными днями (суббота и воскресенье). При этом законодательством определена именно высшая планка нормы, нижняя может устанавливаться по желанию работодателя и трудового коллектива.

Вопрос о введение четырехдневной рабочей недели обсуждается во всем мире. Основанием для введения такой нормы называют снижение эмоциональной и физической нагрузки на человека» [12].

Также говорят о повышении эффективности использования рабочего времени. Действительно на ряде предприятий или в некоторых подразделениях, особенно управленческих, уровень организации производства крайне низок.

«По данным Организации экономического сотрудничества и развития в прошлом году рейтинг стран с наименее загруженным графиком работы возглавили скандинавы - Дания, Норвегия, Швеция. В десятке также Нидерланды, Ирландия, Германия, Швейцария, Бельгия, Австрия и Италия.В странах, занимавших первые позиции, рабочая неделя длится не более 33 часов. В Германии, Швейцарии и Бельгии - 35. Франция - не более 35-36 часов» [13]. Следует отметить, что многие развитые страны, например Япония, Южная Корея и др. работают по 60 и более часов в неделю, что определяется не только менталитетом населения, но и высокой конкуренцией за рабочие места. В некоторых государствах, например США, существует практика, когда люди работают 4 дня при этом по 10 часов в день, тем самым выполняя норму 40 часов в неделю. В большинстве развитых государств также меньше продолжительность годового фонда рабочего времени, гибкие графики отпусков и отгулов, больше праздничных дней.

«13 августа 2019 года Федерация независимых профсоюзов России (ФНПР) выступила с предложением внедрить на территории страны четырехдневную рабочую неделю. Данная инициатива была направлена на рассмотрение Министерства труда РФ.По словам заместителя председателя ФНПР Александра Шершукова, несмотря на уменьшение количества рабочих дней, работодатели обязаны сохранить за своими служащими прежний уровень заработной платы.

Эксперимент по переходу на сокращенную рабочую неделю будет проведен на предприятиях, которые участвуют в национальном проекте по повышению производительности. В этот список входит 266 компаний следующих сфер: обрабатывающего производства; сельского хозяйства; научной деятельности; технической деятельности; строительства» [12].

Почему необходимость такого эксперимента и вообще вся идея сокращения рабочей недели вызывает сомнение?

Во-первых, проект создания высокопроизводительных рабочих мест направлен на появление предприятий-лидеров, которые могут значительно повысить выпуск продукции, в том числе и за счет диверсификации и расширения производства в случае полного удовлетворения спроса на основную продукцию при внедрении высокопроизводительного оборудования и технологий. Предполагалось, что опыт таких предприятий по повышению производительности труда и будет передан в отстающие предприятия и отрасли. Это, соответственно, обеспечит выход всей страны на высокие темпы экономического роста. Резерв рынков для производителей достаточен, в том числе в рамках импортозамещения. 
Сокращение же рабочего времени неизбежно ограничит возможности экономического роста без значительных капиталовложений в экономику, позволяющих заменить труд капиталом. Все теоретики экономической мысли говорили об ограниченности такой замены, определяемой уровнем инновационного развития.

Таким образом, с позиции экономического развития учитывая значительное отставание России по макроэкономическим показателям, мы пока не можем позволить себе роскошь сокращения фонда рабочего времени.

Во-вторых, сомнителен также социальный эффект. Появление дополнительно времени на отдых и релаксацию крайне заманчиво, но вызывает вопрос о возможности его рационального и эффективного использования. И, как это не парадоксально может привести к росту девиантного поведения у части населения или поиска дополнительной занятости, еще больше увеличивающей нагрузку на человека.

Также непонятна возможность установления 4 дневной рабочей недели в социально-бюджетной сфере, отраслях с непрерывным циклом производства, где такое нововведение приведет к необходимости роста численности работающих. А с позиции социальной справедливости переход на четырехдневную рабочую неделю должен затронуть все работающее население.

Таким образом, вопрос о введении четырехдневной рабочей недели в России еще не созрел и это дело достаточно отдаленного будущего. В перспективе, при выходе на лидирующие позиции в мире по производительности труда, высокого уровня автоматизации производственных процессов, создании определенного резерва по денежным средствам и, соответственно, по необходимости задействования рабочей силы в экономике, к вопросу сокращения рабочей недели можно вернуться.

\section{Библиография}

1. David Eaves. When Measuring the Digital Economy, Measure the (Creative) Destruction Тоо. [Электронный pecypc]. Режим доступа: https://eaves.ca/2010/11/02/when-measuring-the-digital-economy-measure-the-destructiontoo/.(Дата обращения: 15.10.2019).

2. Стоцкий А. В будущем не придется ни учится, ни работать // Экспресс газета № 20 (1265), 2019. - С. 10 $-11$

3. Брайсон Д, Искусственный и человеческий интеллект // Материалы образовательного интенсива «Остров 10-22». [Электронный ресурс]. Режим доступа: https://ntinews.ru/panorama/video/ (Дата обращения: 15.10.2019).

4. Николай Соломон: Поможем бурятским предприятиям раскрыть колоссальный потенциал // Информполис, №33 (1402), 21.08.2019. С. 11

5. https://ria.ru/20170901/1501566046.html

6. Беломестнов В.Г., Матвеева Г.В. Инновационная и инвестиционная политика предприятий // Экономика, управление и образование: Материалы национальной научно-практической конференции. - Улан-Удэ: Изд-во ВСГУТУ, 2018. - С. $13-14$.

7. Малышев Е.А., Бартош А.А. Рост производительности труда как фактор устойчивого развития экономики // Новая экономическая реальность, кластерные инициативы и развитие промышленности (ИНПРОМ2016) Труды международной научно-практической конференции. под ред. А.В. Бабкина. 2016. С. 63-67.

8. В Госдуме назвали число россиян, которым грозит потеря работы. [Электронный ресурс]. Режим доступа: https://yandex.ru/turbo?text=https\%3A \%2F\%2Fura.news\%2Fnews\%2F1052393950\&d=161095 (Дата обращения: 15.10 .2019$)$.

9. Топилин М. О модернизации системы профессиональных квалификаций. 24.07.2019. [Электронный peсурс]. Режим доступа: http://www.kremlin.ru/events/president/news/61095 (Дата обращения: 15.10.2019).

10. https://ria.ru/20190827/1557933677.html

11. https://www.gazeta.ru/science/ne

12.ws/2016/07/15/n_8885315.shtml

13. http://social-benefit.ru/novosti/chetyrexdnevnaya-rabochaya-nedelya-v-rossii-v-2019-godu/ 